\title{
Inversion for Parameters of Tamarix Chinensis Forest from SAR and InSAR
}

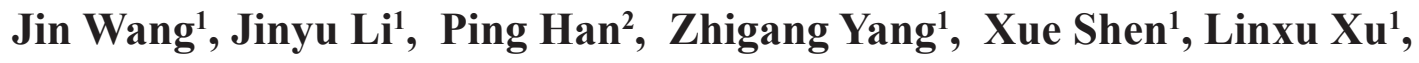 \\ Sisi Xu${ }^{1}$, Bing Liu ${ }^{1}$, Feiyong Chen ${ }^{1 *}$ \\ ${ }^{1}$ Research Institute of Resources and Environment Innovation, Shandong Jianzhu University, Jinan 250101, China \\ ${ }^{2}$ Department of Environmental Engineering, Shandong Urban Construction Vocational College, Jinan, China
}

Received: 29 April 2021

Accepted: 18 September 2021

\begin{abstract}
The parameters, including diameter at breast height and tree height of tamarix chinensis forest in the study area, were inversed on basis of backscatter coefficient, polarimetric SAR, differential interferometry with DEM, and differential interferometry with polarization. Finally, main conclusions are shown in the following: (1) The backscatter coefficient of SAR image was influenced by stand structure, phenological change and polarization way. Especially, the correlation was as high as 0.82 between the backscatter coefficient of $\mathrm{VV}$ polarization and vegetation fractional coverage. (2) The inversed tree height by differential interferometry with DEM and differential interferometry with polarization were three quarters and a half of the measured tree height. The reason of underestimation by these two methods was the uncertain interferometric phase of canopy surface and land surface during inversion. (3) After the calibration by the compensation model with sinc function, the average difference was $0.56 \mathrm{~m}$ between the calibrated tree height and the measured tree height, and relative error was $17.17 \%$, so the inversed results were closer to the measured tree height. Therefore, the research results of this article can provide scientific basis and technical guidance for the protection, survey statistics, and ecological renovation of the tamarix chinensis forest in protection zone.
\end{abstract}

Keywords: tamarix chinensis forest, backscattering coefficient, differential interferometry, tree height

\section{Introduction}

As a worldwide and mature technology in the field of forest monitoring, although optical remote sensing is able to offer abundant information, referring to spectrum, texture and horizontal distribution of forest canopy, it still has an obvious disadvantage of being

*e-mail: 24254@sdjzu.edu.cn influenced by cloudy and foggy weather. Meanwhile, it is hard for normal optical sensor to extract the information in the vertical direction of forest [1]. By contrast, radar sensor can not only acquire information of forest vertical structure for forest measurement, but also be less influenced by atmospheric condition [2, 3]. According to existed study, the backscatter coefficient based on SAR can be utilized for the inversion of the forest height, $\mathrm{DBH}$ (diameter at breast height) and forest volume and biomass [4, 5]. Moreover, due to the phase information besides strength information 
in SAR image, it is possible to realize the inversion of forest vertical information through InSAR, DInSAR (Differential InSAR), PolInSAR (Polarimetric InSAR) and TomoSAR [6-8].

Taking the tamarix chinensis forest in Changyi national marine ecological special reserve in Shandong province, China, as study objective, the parameters of tamarix chinensis forest, including diameter at breast height $(\mathrm{DBH})$ and tree height, were inversed on basis of backscatter coefficient, polarimetric SAR, differential interferometry with DEM, and differential interferometry with polarization in this research. Research results can provide scientific basis and technical guidance for the protection, survey statistics, and ecological renovation of the tamarix chinensis forest in protection zone.

\section{Material and Methods}

\section{Study Area}

The study area of tamarix chinensis forest ranges from the dampproof dam of salt field of National Defense University in the east to the embankment of Di river in the west, reaches to the branch of Di river in the south, and shares the same border with the shallow sea area in the north. The study area, approximate $1548 \mathrm{hm}^{2}$, is $5000 \mathrm{~m}$ wide from east to west, and $7000 \mathrm{~m}$ long from south to north. In this research, field investigation happened on September 9th, 2019. The $\mathrm{DBH}$ of tamarix chinensis forest was diameter of tree height at $1.3 \mathrm{~m}$, and handheld telescope of laser ranging and altimeter (SNDWAY /SW-1200A) was used to measure the crown width and tree height. The location of study area and sampling point of Tamarix parameter can be found in Fig. 1. The measure results can be found in Table 1 .

\section{Extraction of Backscatter Coefficient}

The data sources used for the extraction of backscattering coefficient in this study were Sentinel1A SLC data with C-band. Firstly, initial SAR data were transformed into intensity image through multilook processing. Next, intensity image was denoised by De Grandi Multi-temporal filter. Lastly, through radiation calibration and geocoding, the image data was converted into backscatter coefficients which could be compared under the same standard. Because the result of radiation calibration was non-dimensional and the order of magnitude of backscatter coefficient was lower. For the convenience of analysis, the intensity data of backscatter coefficient was transformed into Sigma backscatter coefficient in $\mathrm{dB}$ units [9].

\section{Interferometric Processing of SAR Images}

The data sources used for InSAR technology in this study were Sentinel-1A SLC data with C-band and ALOS-1 PALSAR data with L-band. Firstly, the baseline between the main image and the slave images were estimated before interferometric processing. When baseline length was inferior to one third of critical baseline length, SLC data would be processed by registration and multi-look to get the interferogram with removing flat-earth effect [10]. Then, adaptive filtering method was taken to remove phase noise and the correlation coefficient was calculated. Next, minimum cost flow method was applied for phase unwrapping, and orbit refinement and re-flattening were conducted with selected ground control points (GCPs). In order to remove terrain phase, the GCPs distributed in the whole protection zone should meet the conditions without dense interference fringe and phase jump, with high coherence. Lastly, the research took advantage of geocoding to obtain the interferometric
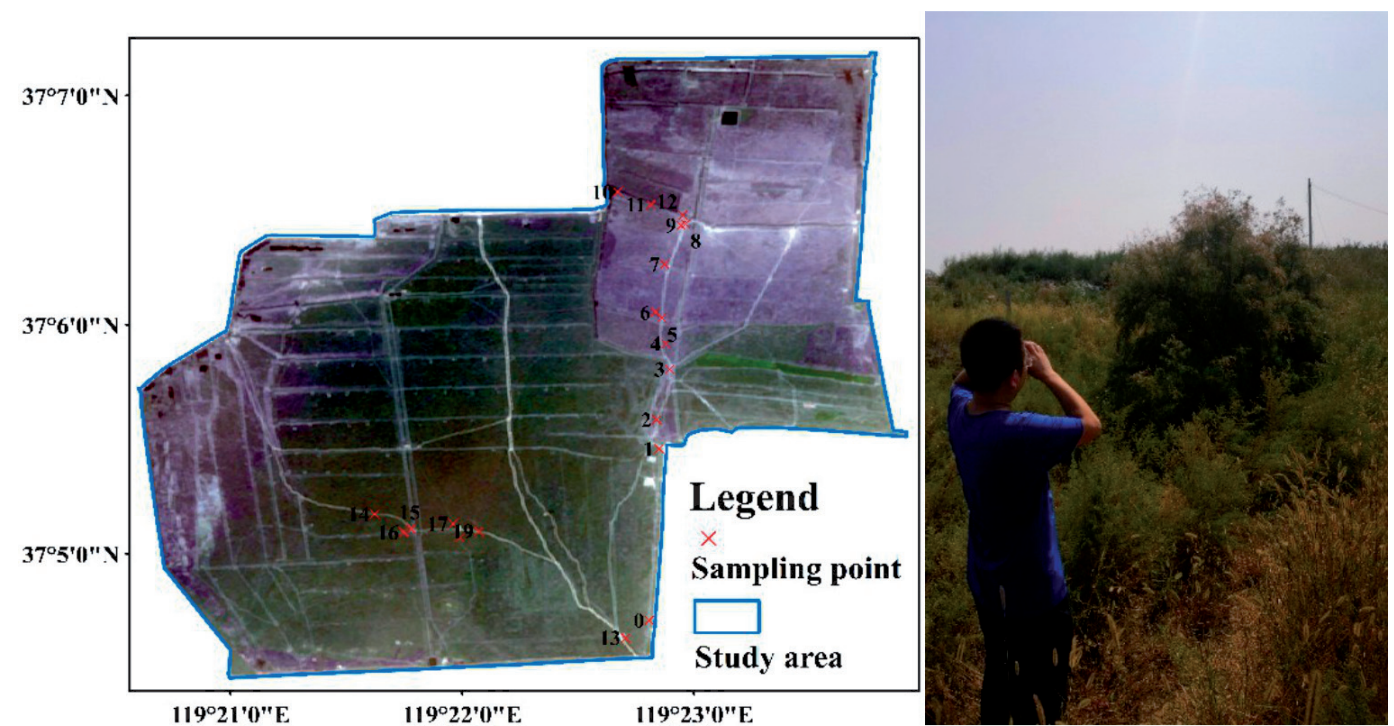

Fig. 1. Location of study area and sampling point of Tamarix parameter (L), field survey (R). 
Table 1. The measured values of Tamarix parameters in study area.

\begin{tabular}{|c|c|c|c|c|c|c|c|}
\hline \multirow{2}{*}{ No. } & \multirow{2}{*}{ Longitude } & \multirow{2}{*}{ Latitude } & \multirow{2}{*}{ Tamarix number } & \multirow{2}{*}{$\mathrm{DBH} / \mathrm{cm}$} & \multicolumn{2}{|c|}{ Crown width/m } & \multirow{2}{*}{ Tree height/m } \\
\hline & & & & & EW & NS & \\
\hline 0 & 119.380107 & 37.078478 & 1 & 20.1 & 4.7 & 3.8 & 3.6 \\
\hline 1 & 119.380826 & 37.090939 & 3 & 18.5 & 6.3 & 6.9 & 3.0 \\
\hline 2 & 119.380634 & 37.093073 & 1 & 20.6 & 3.3 & 3.1 & 3.8 \\
\hline 3 & 119.381592 & 37.096755 & 1 & 7.3 & 3.8 & 4.0 & 3.1 \\
\hline 4 & 119.381311 & 37.098625 & 2 & 11.0 & 4.5 & 7.1 & 4.0 \\
\hline 5 & 119.381030 & 37.100494 & 2 & 5.2 & 1.4 & 3.1 & 2.8 \\
\hline 6 & 119.380558 & 37.100884 & 1 & 5.1 & 2.9 & 3.0 & 2.7 \\
\hline 7 & 119.381222 & 37.104371 & 1 & 5.0 & 2.9 & 2.7 & 2.1 \\
\hline 8 & 119.382724 & 37.107301 & 1 & 15.9 & 3.4 & 3.6 & 3.2 \\
\hline 9 & 119.382413 & 37.107218 & 1 & 4.0 & 0.5 & 0.6 & 1.0 \\
\hline 10 & 119.377853 & 37.109638 & 1 & 4.6 & 2.0 & 1.9 & 1.8 \\
\hline 11 & 119.380228 & 37.108734 & 2 & 7.1 & 4.2 & 4.5 & 3.0 \\
\hline 12 & 119.382523 & 37.107937 & 1 & 4.7 & 2.1 & 2.2 & 1.9 \\
\hline 13 & 119.378419 & 37.077216 & 2 & 6.5 & 3.5 & 3.6 & 2.8 \\
\hline 14 & 119.360358 & 37.086210 & 3 & 19.7 & 5.0 & 2.4 & 4.2 \\
\hline 15 & 119.362982 & 37.085147 & 2 & 16.1 & 4.2 & 6.8 & 4.0 \\
\hline 16 & 119.362458 & 37.084881 & 3 & 15.2 & 3.1 & 3.5 & 3.2 \\
\hline 17 & 119.366013 & 37.085501 & 3 & 17.9 & 3.3 & 5.3 & 3.6 \\
\hline 18 & 119.366506 & 37.084493 & 2 & 21.6 & 2.3 & 3.4 & 4.6 \\
\hline 19 & 119.367856 & 37.084962 & 1 & 6.4 & 2.2 & 2.3 & 2.5 \\
\hline
\end{tabular}

observation results under WGS-84 geographic coordinate system.

\section{Results and Discussion}

Characteristic Analysis of Backscatter Coefficient of Tamarix Chinensis Forest

\section{The Influence Factors of Backscatter Coefficient}

According to previous study, in the inversion of vegetation parameters, the backscatter coefficient of SAR image would be influenced by forest height, stand structure, vegetation water content, phenological change, and so on [11, 12]. Based on the preprocessing of SAR images, the ROI (Region of Interest) with different VFC and time phase were selected to contrastively analyze the backscatter coefficient of the tamarix chinensis forest in protection zone.

Fig. 2 includes the backscatter coefficient of Sentinel-1A image under different VFC and the same time phase on September $9^{\text {th }}$, 2019. It can be found from the figure that backscatter coefficients of both
VV image and VH image all increase with the growth of VFC. It is worth noting that, for VV image, the correlation between backscatter coefficient and VFC reaches up to 0.82 .

Fig. 3 demonstrates the backscatter coefficient of the same pixel $\left(65 \%\right.$ VFC on September, $\left.9^{\text {th }}, 2019\right)$ in the tamarix chinensis forest at different time phases in 2019. Shown by the figure, no matter in VV or VH polarization image, the maximum backscatter coefficient appeared in June or September, and the minimum was found in April. According to the analysis, study area was abundant in precipitation during June to September. So the tamarix chinensis forest grows vigorously in the spring and the summer. But in April, the tamarix chinensis forest was with the lower temperature environment, and soil water content was low just after the winter. Besides, backscatter coefficient obviously increased from April to June. During this period when the weather gradually warmed, tree growth entered into peak season, so there was relatively obvious variation in some tree-related parameters of water content, DBH and height, which led to distinctly change of backscatter coefficient of tamarix chinensis forest in protection zone. 


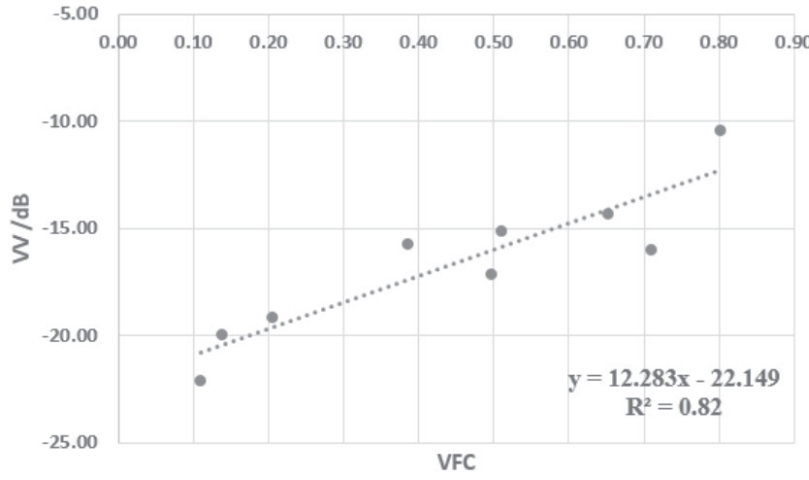

Fig. 2. The backscattering coefficient with different VFC.

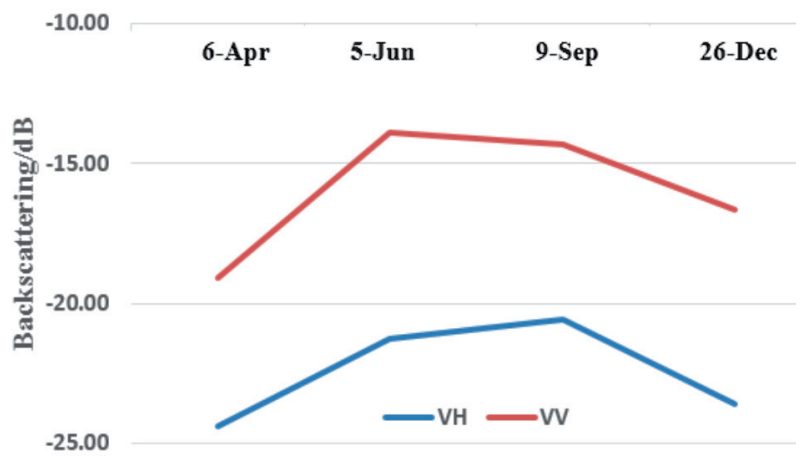

Fig. 3. The change of backscattering coefficient of the same pixel at different time phases.

\section{Polarimetric SAR}

Electromagnetic wave is classified into horizontal wave $(\mathrm{H})$ and vertical wave $(\mathrm{V})$ in both emission and reception. So the so-called full polarization mode has at most four modes of horizontal emission and reception $(\mathrm{HH})$, horizontal emission and vertical reception (HV), vertical emission and reception (VV) and vertical emission and horizontal reception (VH). In this study, the data source of Sentinel-1A polarization image on September $9^{\text {th }}, 2019$, dual polarization SAR image, has VV and $\mathrm{VH}$ polarization mode at the same time.

As can be seen from Fig. 4, polarization mode also affects the backscattering coefficient. By contrast, the vegetation in protection zone has relatively homogeneous tone in $\mathrm{VH}$ polarization image, but rough tone in $\mathrm{VV}$ polarization image. In terms of field investigation, the shrubwood of tamarix chinensis in study area has high VFC. Because of the high VFC and weak penetrability of $\mathrm{VH}$ polarization wave, what $\mathrm{VH}$ polarization reflects is mainly the vegetation canopy information with homogenous tone. However, VV polarization wave is relative strong in penetrability, so VV polarization reflects the vegetation information of vegetation canopy, structure of tree trunk, the wetness and roughness of roads and soil in a certain extent [13].

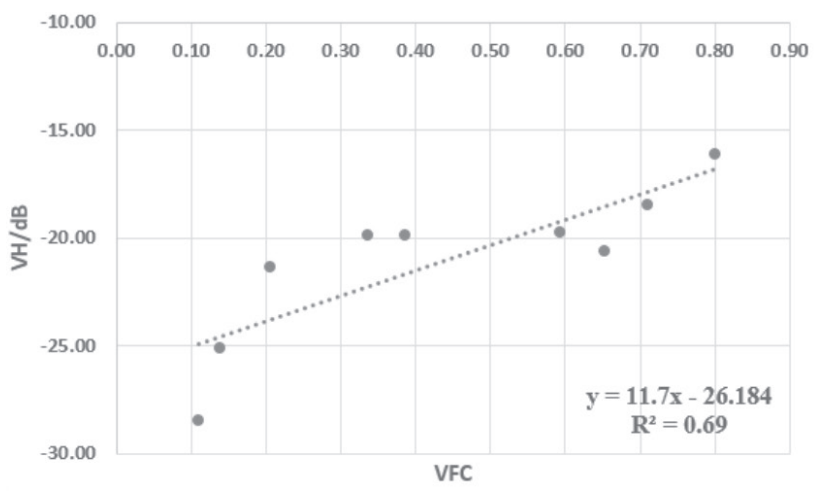

Vegetation Parameter Inversion
with Backscatter Coefficient

This research extracted backscatter coefficient from the $\mathrm{VV}$ and $\mathrm{VH}$ polarization SAR image taken on September $9^{\text {th }}, 2019$, and built the Inversion model between backscatter coefficient and the measured tree height and DBH. In consideration of the bigger pixel with spatial resolution of $20 \times 20 \mathrm{~m}$, the parameters were the mean value of all the tamarix chinensis forest in the same pixel. Previous studies have shown that logarithmic function model is the most common model for estimating parameters for tree [14]. Therefore, the inversion model of the relationship between backscatter coefficient and tree height and DBH is established as follows:

$$
\mathrm{y}=\mathrm{a} \times \ln (\mathrm{x})+\mathrm{b}
$$

Where y refers to backscatter coefficient, $a$ and $b$ are related coefficients, and $\mathrm{x}$ means the measured tree height or DBH. This model is used to get the relationship between backscatter coefficient and the $\mathrm{DBH}$ and tree height. As shown in Fig. 5, the correlations are both 0.39 for $\mathrm{VV}$ image, and respectively 0.55 and 0.39 for $\mathrm{VH}$ image. The highest correlation is just 0.55 between $\mathrm{DBH}$ and backscatter coefficient in $\mathrm{VH}$ image, and the correlations between backscatter coefficient and the other parameters belong to weak correlation. This is because the $\mathrm{VH}$ polarization is weak in penetrability, and the scattering phase which represents the vegetation canopy of tamarix chinensis is predominant in echo. Therefore, it is largely limited to push the inversion model with backscatter coefficient on a large scale, because tree height and $\mathrm{DBH}$ obtained through this model are relatively low in precision.

\section{The Application of InSAR on Height Inversion of Tamarix Chinensis Forest}

\section{Differential Interferometry with DEM}

In terms of measurement theory of InSAR technology, if the scattering characteristic of ground object and the different effect factors in electromagnetic 


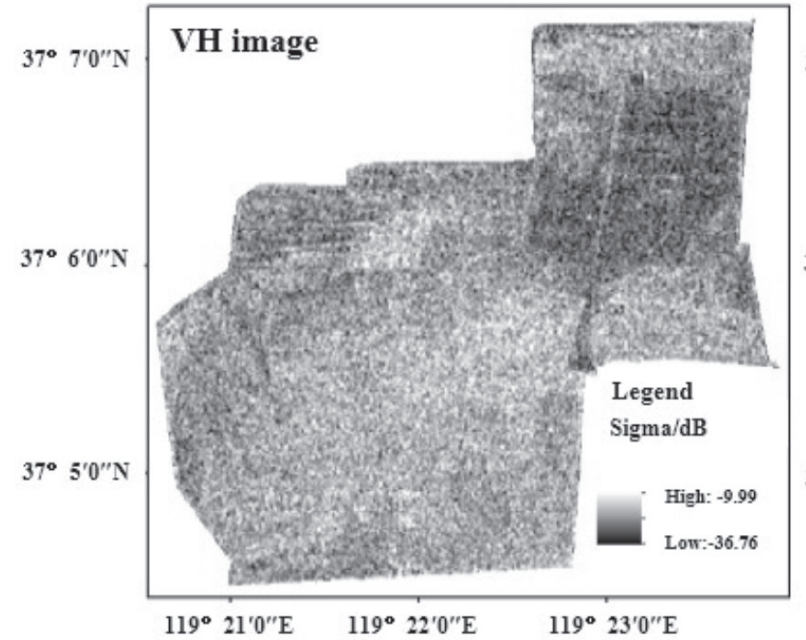

$119^{\circ} 21^{\prime} 0^{\prime \prime} \mathrm{E} \quad 119^{\circ} 22^{\prime} 0^{\prime \prime} \mathrm{E} \quad 119^{\circ} 23^{\prime} 0^{\prime \prime} \mathrm{E}$

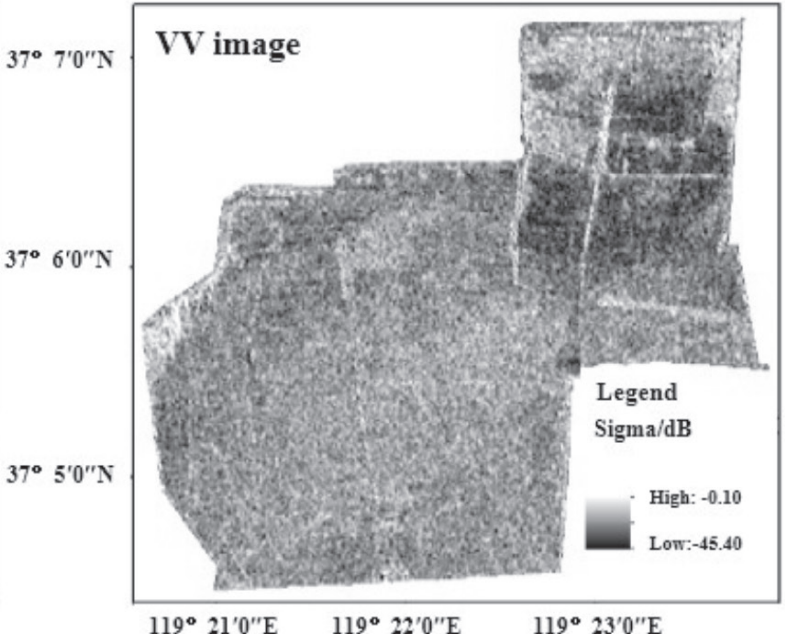

$119^{\circ} 21^{\prime} 0^{\prime \prime} \mathrm{E} \quad 119^{\circ} 22^{\prime} 0^{\prime \prime} \mathrm{E} \quad 119^{\circ} 23^{\prime} 0^{\prime \prime} \mathrm{E}$

Fig. 4 The backscattering with different polarization ways.

wave transmission can be inhibited, it is possible to make sure the elevation of corresponding point by means of the interferometric phase with twice measurements [1517]. In the region covered by vegetation, the obtained elevation information through InSAR technology cotains the height of scattering center of vegetation [18]. Thus, forest height can be inversed through InSAR and the RVoG (Random Volume over Ground) model [19].

Different wavelengths of microwave will cause the obvious difference of phase center of forest, so it is necessary to select suitable measurement methods for different wavebands [20,21]. Until now, the common bands of SAR image includes $\mathrm{X}$ band $(2.4-3.8 \mathrm{~cm}), \mathrm{C}$ band $(3.8-7.5 \mathrm{~cm}), \mathrm{S}$ band $(7.5-15 \mathrm{~cm}), \mathrm{L}$ band $(15-30 \mathrm{~cm})$ and $\mathrm{P}$ band $(30-100 \mathrm{~cm})$. For $\mathrm{P} / \mathrm{L}$ band, it is featured by long wave, strong penetrability in forest, and scattering phase center closer to land surface. However, for $\mathrm{X} / \mathrm{C}$ band, it has short wave, its scattering is mainly dominated by canopy leaves and the scattering phase center locates in forest canopy. In this way, in the same region with both $\mathrm{P} / \mathrm{L}$ band SAR images and $\mathrm{X} / \mathrm{C}$ band SAR images, the phase center difference or so-called differential interferometry with DEM, can be used to extract forest height. In the region only with $\mathrm{X} / \mathrm{C}$ band SAR images, if there exist precise elevation data of
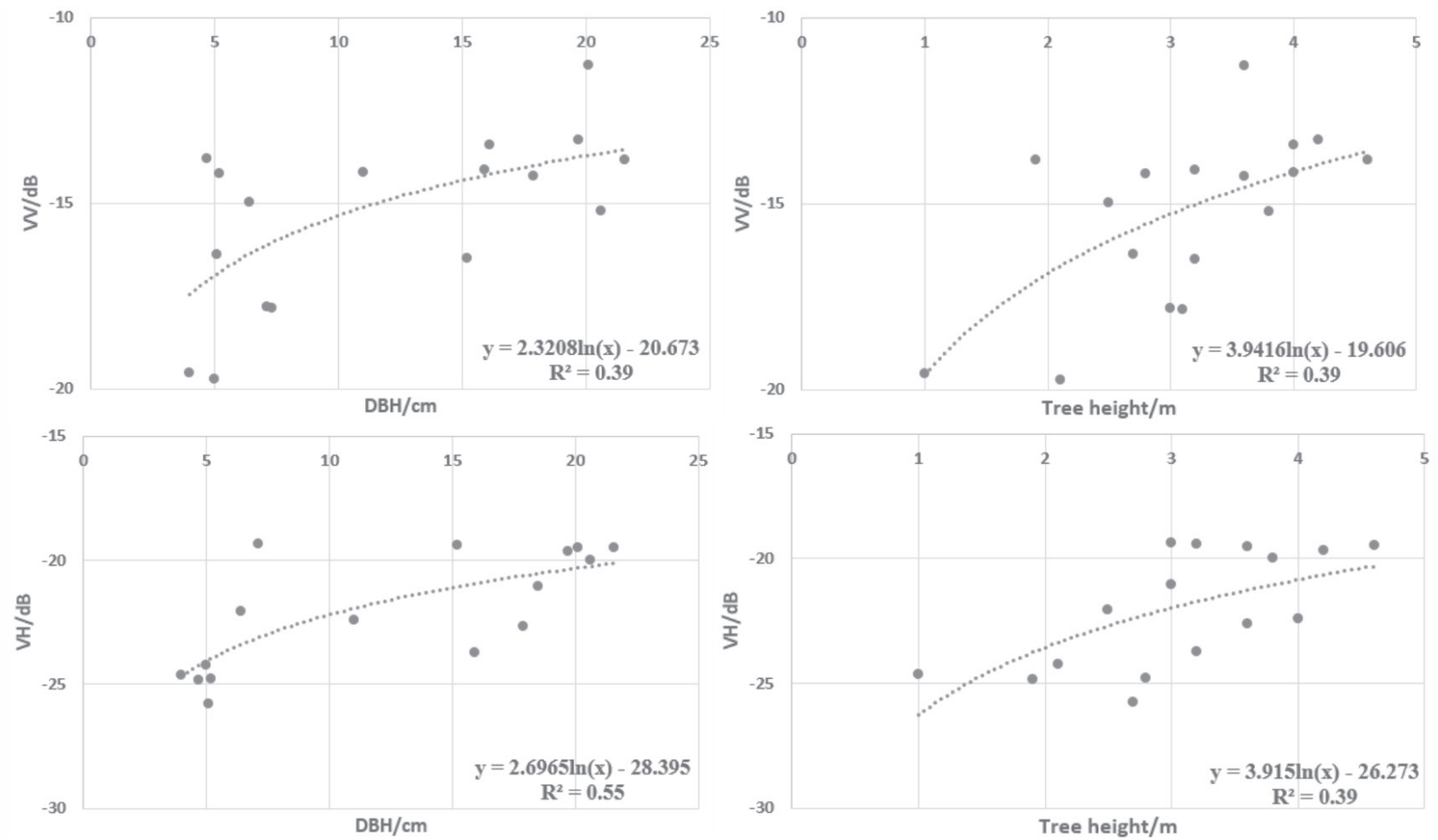

Fig. 5. The correlation between DBH, tree height and backscatter coefficient. 


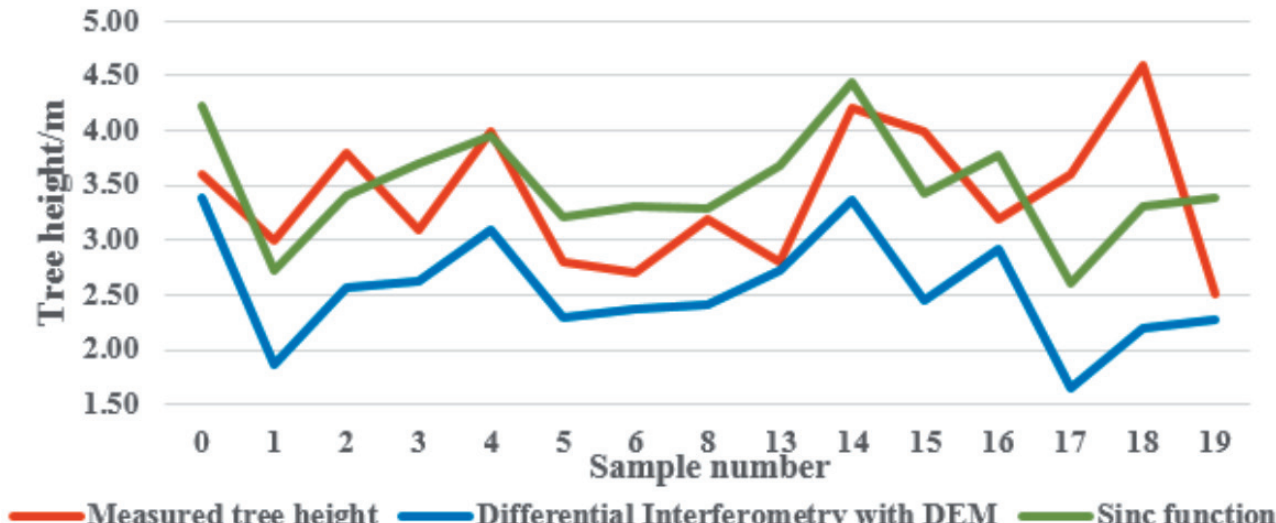

Fig. 6. The extracted results of tree height by differential interferometry with DEM and compensation model with Sinc function.

Note: The sample number in Figure 6 and Figure 7 corresponds to the position and number in Table 1 and Figure 1 . Due to the corresponding pixels of sample number 7, 9, 10,11 and 12 were incoherence in interferometric processing, so the tree height of sample points are not inversed.

digital elevation model (DEM), it is possible to extract forest height with the difference between scattering phase center of $\mathrm{X} / \mathrm{C}$ band and DEM data [22].

Form Fig. 6, on the basis of the ALOS PALSAR-1 L-band images and the Sentinel-1 C-band images, the measured tree height is bigger than that extracted by differential interferometry with DEM, the inversed results are three quarters of the measured value, the difference is about $0.86 \mathrm{~m}$, which occupies $25.32 \%$ in relative error, between the average inversed height of 15 sampling points and the average measured height. This is because the land surface phase represented by interference with L-band images is higher than actual land surface phase and the canopy phase represented by interference with C-band images is lower than actual canopy phase [23].

\section{Differential Interferometry with Polarization}

Polarization information of SAR image is sensitive to the shape and direction of vegetation scatterer.
Meanwhile, interferometric information of SAR image is sensitive to the spatial distribution and height of vegetation scatterer. So the combination of polarization information and interferometric information extremely enlarges interferometric information source of SAR image, and expands the dimensions of inversion of vegetation parameter through InSAR technology. From the perspective of SAR image characteristics with different polarization mode at the same band, echo intensity and penetrability of cross-polarization is weaker than that of co-polarization. In this study for the tamarix chinensis forest in protection zone, the interferometric phase of $\mathrm{VH}$ cross-polarization and $\mathrm{VV}$ co-polarization corresponds to different tree height [24]. Ideally, the echo of $\mathrm{VH}$ polarization is mainly dominated by the phase representing canopy scattering, and the echo of VV polarization is mainly dominated the phase representing land surface scattering. Thus, it is theoretically feasible to obtain the elevation difference between canopy surface and land surface by differential polarization interferometry mode [25]. Based on this,

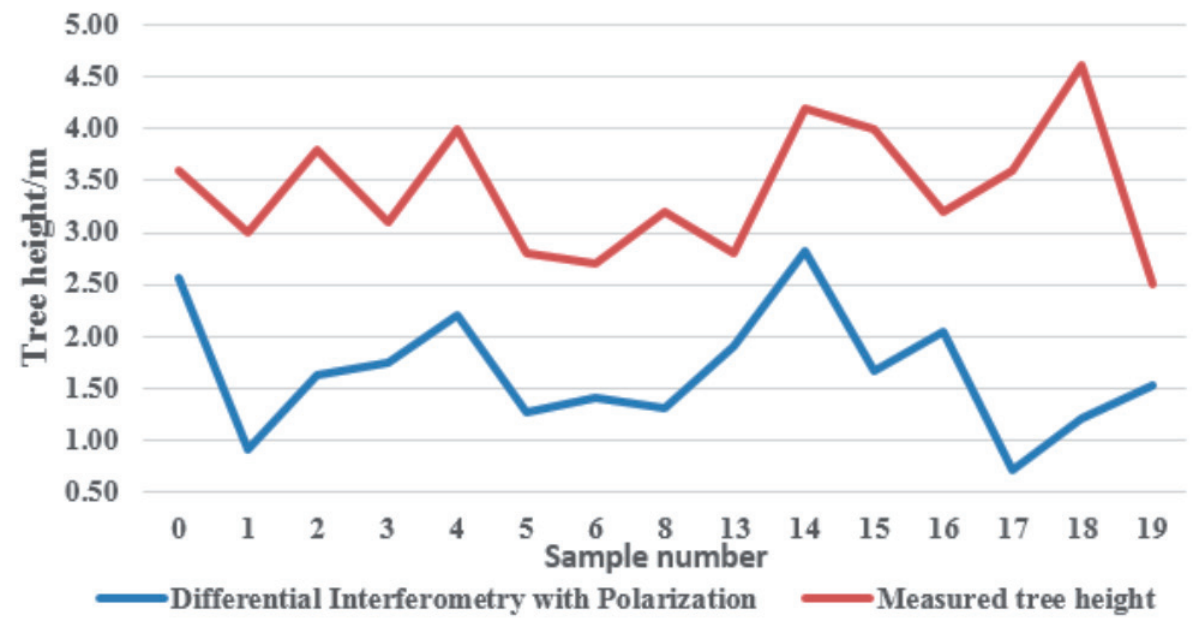

Fig. 7. The extracted results of tree height by differential Interferometry with polarization. 
the tree height of the tamarix chinensis forest could be extracted by using VH and VV polarization data of Sentinel-1A image taken on September, $9^{\text {th }}, 2019$.

As shown in Fig. 7, the inversed results of tree height by differential interferometry with polarization is only about a half of the measured value, the average difference of 15 sampling points is $1.74 \mathrm{~m}$ between the inversed tree height and the measured value, and relative error reaches to $51.13 \%$. Hence, the inversed results obtained by differential interferometry with polarization is lower and has bigger relative error than the inversed results extracted by differential interferometry with DEM. On underestimation of the inversed results of tree height, it is mainly caused by the uncertainty of the canopy phase center of $\mathrm{VH}$ polarization and the land surface phase of VV polarization. When considering the specific structure of tamarix chinensis forest, in the actual inversion process of vegetation height, the scattering phase center of $\mathrm{VH}$ polarization is located in the position between canopy top and trunk, and the scattering phase center of $\mathrm{VV}$ polarization is located above the land surface [26, 27].

\section{Compensation Model with Sinc Function}

The above results show that the measured tree height is bigger than the inversed tree height by differential interferometry with DEM and differential interferometry with polarization. Moreover, the previous study has proved that this phenomenon is mainly because vegetation scattering phase is not calibrated in the inversion process. Therefore, when the amplitude corresponding to the land surface phase in RVoG model is close to zero, the coherence coefficient of amplitude is only related to scatterer of vegetation, which means that the coherence coefficient of amplitude is only related with tree height [28]. Then, Sinc function can be used to build a compensation model of tree height with coherence coefficient. In this research, tree height compensation model of Sinc function was built with the VH polarization image of Sentinel-1A SLC data, which taken on September $9^{\text {th }}, 2019$ and has relatively low amplitude corresponding to the land surface phase [29]. At last, the final inversed results of tree height were the summation of the inversed height respectively through differential interferometry with DEM and the compensation model of Sinc function using coherence coefficient.

The inversed tree height of the tamarix chinensis forest by using compensation model with Sinc function can be seen from Fig. 6. It shows that the difference of 15 sampling points is within the range of $0.03 \mathrm{~m}$ to $0.89 \mathrm{~m}$ between the inversed results of tree height and the measured value, and the average difference of tree height between the inversed results and the measured value is $0.56 \mathrm{~m}$, equal to $17.17 \%$ of relative error. In short, compared with the inversed tree height obtained through differential interferometry with DEM and differential interferometry with polarization, the inversed tree height extracted by compensation model with Sinc function is higher in precision, closer to the actual value.

\section{Conclusions}

In this research, the parameters of tamarix chinensis forest in the study area, including $\mathrm{DBH}$ and tree height, were inversed based on backscatter coefficient, polarimetric SAR, differential interferometry with DEM, and differential interferometry with polarization. Finally, main conclusions are shown in the following:

(1) In the inversion process of tamarix chinensis forest parameters through the backscatter coefficient of SAR image, the coefficient of correlations of VV image and $\mathrm{VH}$ image all increased with the growth of VFC in protection zone on the same time phase on September $9^{\text {th }}, 2019$. Especially, the correlation was as high as 0.82 between the backscatter coefficient of $\mathrm{VV}$ polarization and VFC.

(2) Due to the influence factors of rainfall, temperature and growth cycle, backscatter coefficient reached to the maximum in June or September, the minimum in April, and the period of significant change from April to June in the same pixel $(65 \%$ VFC on September 9th, 2019). The correlation between backscatter coefficients of $\mathrm{VV}$ image and $\mathrm{DBH}$, tree heigh were both 0.39 , and respectively 0.55 and 0.39 for $\mathrm{VH}$ image. Obviously, it is largely limited to push the inversion model with backscatter coefficient on a large scale.

(3) Through differential interferometry with DEM, the inversed tree height was three quarters of the measured tree height, the average difference was $0.86 \mathrm{~m}$ between the inversed and the measured tree height, and relative error reached to $25.32 \%$. With the help of differential interferometry with polarization, the inversed tree height was only a half of the measured tree height, the average difference was $1.74 \mathrm{~m}$ between the inversed and the measured tree height, and relative error reached to $51.13 \%$. The underestimation of these two methods was mainly caused by the uncertain interferometric phase of canopy surface and land surface during inversion.

(4) After the calibration by the compensation model with Sinc function, the average difference was $0.56 \mathrm{~m}$ between the calibrated tree height and the measured tree height, and relative error was $17.17 \%$. This showed the inversed results were closer to the measured tree height.

\section{Acknowledgments}

This research was funded by the National Science Fund for Distinguished Young Scholars - "Construction and application of remote sensing ecological index model of Tamarix shrubbery forest (grant number 42107496)", the project of "One Project One Discussion" 
on intro-ducing top talents in Shandong Province "Research and development of key technologies and high-end equipment of water environment health in the Yellow River Basin (Shandong)" and the Doctoral research fund project of Shandong Jianzhu University - "Research on ecological environment quality assessment of Tamarix chinensis forest in Changyi based on Remote Sensing Technology", grant number X20192Z".

\section{Conflict of Interest}

The authors declare no conflict of interest.

\section{References}

1. JUGAL K.M., VARGHESE A.O. Remote Sensing and GIS in Agriculture and Forest Resource Monitoring. Geospatial Technologies in Land Resources Mapping, Monitoring and Management, 19, 377, 2018.

2. LI W., LI Z., CHEN E., FENG Q. Status and development of tomographic SAR for forest vertical structural parameters inversion. J. Remote Sens., 18 (4), 742, 2014.

3. ALONSO G.A., HAJNSEK I. Radar Remote Sensing of Land Surface Parameters. Ob. and Measurement, 2, 1, 2018.

4. WANG Y., DAY J.L., DAVIS F.W. Sensitivity of modeled C and $\mathrm{L}$ band radar backscatter to ground surface parameters in loblolly pine forest. Remote Sens. Environ., 66 (3), 331, 1998.

5. VUET L.N., TU T.T., SON L.M. Relationship between tropical forest biomass, woody volume and backscattering intensity of ALOS-2 SAR data. Environ. Earth sci., 3 (1), 1035, 2020.

6. KUGLER F., LEE S.K., HAJNSEK I., PAPATHANASSIOU K.P. Forest Height Estimation by Means of Pol-InSAR Data Inversion: The Role of the Vertical Wavenumber. IEEE T. Geosci. Remote Sens., 53 (10), 5294, 2015.

7. XING M., LU Z., YU H. InSAR Signal and Data Processing. Sensors, 20 (13), 1, 2020.

8. WAN J., WANG C., SHEN P., HU J., ZHU J. Forest Height and Underlying Topography Inversion Using Polarimetric SAR Tomography Based on SKP Decomposition and Maximum Likelihood Estimation. Forests, 12 (4), 444, 2021.

9. VERMA A., KUMAER, A., LAL K. Kharif crop characterization using combination of SAR and MSI Optical Sentinel Satellite datasets. J Earth Syst Sci., 128 (230), 1, 2019.

10. HADJ S.O., FIZAZI H., BERRICHI F., CHAMAKHI D., KEBIR L.W. High-resolution DEM building with SAR interferometry and high-resolution optical image. Institution of Eng. Technol., 13 (5), 713, 2019.

11. MARTINEZ A.A., ALVAREZ M.J., LIEVENS H., VERHOEST N., GIMENEZ R. Influence of Surface Roughness Sample Size for C-Band SAR Backscatter Applications on Agricultural Soils. IEEE Geosci. Remote S., (99), 1-5, 2017.

12. JI Y., HUANG J., JU Y., GUO S., YUE C. Forest structure dependency analysis of L-band SAR backscatter. PeerJ, $\mathbf{8}$, $1,2020$.
13. SHUANG M., HAN Y., HUANG M., WANG Y., MIAO M.W., JIN L. Study on Information and Model of High Polarization Hyperspectral about Vegetation-Soil Mixed Pixels Based on Different Vegetation Indices. Spectrosc. Spect. Anal., 37 (11), 3549, 2017.

14. TSOLMON R., TATEISHI R., TETUKO J.S.S. A method to estimate forest biomass and its application to monitor Mongolian Taiga using JERS-1 SAR data. In. J. Remote Sens., 23 (22), 4971, 2002

15. DREWS R., RACK W., WESCHE C., HELM V. A Spatially Adjusted Elevation Model in Dronning Maud Land, Antarctica, Based on Differential SAR Interferometry. IEEE T. Geosci. Remote Sens., 47 (8), 2501, 2009.

16. XUAN M.T., MINH N.P., THI Y.H., TRUNG T.N Modified Three-stage algorithm for forest height estimation using Polarimetric SAR Interferometry Image. 2018 International Conference on Advanced Technologies for Communications. 37, 2018.

17. CANDO J.M., MARTINEZ G.A. Differential interferometry, structural lineaments and terrain deformation analysis applied in Zero Zone 2016 Earthquake (Manta, Ecuador. Environ. Earth Sci., 78 (16), $1,2019$.

18. WANG Y., SONG Y., HONG W., ZHANG Y., LIN Y., LI Y., BAI Z., ZHANG Q., LV S., LIU H. Ground-Based Differential Interferometry SAR: A Review. IEEE Geos. Rem. Sen. M., 8 (1), 43, 2020.

19. ONUR Y., ESRA E., IRENA H. Assessment of Paddy Rice Height: Sequential Inversion of Coherent and Incoherent Models. IEEE J-STARS, 99, 1-13, 2018.

20. BALZTER H., ROWLAND C.S., SAICH P. Forest canopy height and carbon estimation at Monks Wood National Nature Reserve, UK, using dual-wavelength SAR interferometry. Remote Sens. Environ., 108 (3), 224, 2007.

21. JOHANSSON A.M., KING J.A, DOULGERIS A.P., GERLAND S., SINGHA S. SPREEN G. BUSCHE T. Combined observations of Arctic sea ice with nearcoincident colocated X-band, C-band, and L-band SAR satellite remote sensing and helicopter-borne measurements. J. Geophys. Res-Oceans, 122 (1), 669, 2017.

22. PERSON H., JORGEN W., HAKAN O., JOHAN E.S.F. Estimating biomass and height using DSM from satellite data and DEM from high-resolution laser scanning data. Geoscience \& Remote Sensing Symposium. IEEE, 12, 1649, 2012.

23. TIGHE M.L., KING D., BALZTER H., MCNAIRN H. Comparison of X/C-HH InSAR and L-PolInSAR for Canopy Height Estimation in a Lodgepole Pine Forest. POLINSAR 2009, 4th International Workshop on Science and Applications of SAR Polarimetry and Polarimetric Interferometry, ESRIN, Frascati, Italy, 2009.

24. ZHANG L., LI X., DU H., MA H., GUO H. Coherent polarimetric SAR simulation of maize. J. Remote Sens., 14 (4), 621, 2010

25. LI H., WANG Y., LUO X. Tree height estimation at plateau mountains, northwestern Sichuan, China using dual PolInSAR data. IGARSS 2016-2016 IEEE International Geoscience and Remote Sensing Symposium, 4698, 2016.

26. WENXUE F., HUADONG G., XINWU L., BANGSEN T., ZHONGCHANG S. Extended Three-Stage Polarimetric SAR Interferometry Algorithm by Dual-Polarization Data. IEEE T. Geosci. Remote Sens., 54 (5), 2792, 2016.

27. CHEHADA B.E.H., FERO F.L., TEBALDINI S., DINH H.T.M.,THUY L.T Comparison of tropical forest Above Ground Biomass estimation techniques based on 
Polarimetric and Tomographic SAR data acquired at $\mathrm{P}$ band. 2017 European Radar Conference (EURAD). IEEE, 2018.

28. CHEN W., ZHENG Q., XIANG H., CHEN X. SAKAI T. Forest Canopy Height Estimation Using Polarimetric Interferometric Synthetic Aperture Radar (PolInSAR)
Technology Based on Full-Polarized ALOS/PALSAR Data. Remote Sens., 13 (2), 174, 2021.

29. OYAMAKIN S.O., CHUKWU A.U. On Hyperbolic Sine Function in Height-diameter Modeling of Gmelina Arborea. Int. J. Modern Math. Sci., 12 (3), 139, 2014. 